\title{
Access and the New Protectionism: What Future for GATTery and All GATT?
}

\section{Reginald Herbold Green}

Third World nations did not shape the world's institutions of production and exchange and have virtually no say in them. But we are dominated by them. It is this domination by forces over which we have no control that each one of us has rejected. And our coming together in the Group of 77 has the purpose of enabling us to deal on terms of greater equality with an existing Centre of Power. Ours is basically a unity of opposition. And it is a unity of nationalisms . . . The immediate interests, and the negotiating priorities of different Group of 77 members are therefore very different. Consequently there is a tendency for sub-groups to develop . . . [which] can be useful; it enables us to carry on particular detailed negotiations with the industrialised countries . . . to ensure that all interests within the Group of 77 are covered . . . But this kind of sub-division is also very dangerous... . 'Divide and Rule' is an old technique of domination; the developed countries are not unaware of its usefulness.

$$
\text { J. K. Nyerere }
$$$$
\text { (in UNCTAD (1) 1979, Annex II: 2-3) }
$$

\section{Trade after Tokyo}

The Manila UNCTAD was not the only forum in which Third World attempts to achieve international economic change met a stone wall (or feather pillow) unwillingness to negotiate substantively in $1979 .{ }^{1}$ Equally disappointingand potentially more dangerous-was the Tokyo Round of multilateral trade negotiations (MTN). While UNCTAD is perceived by the Group of $\mathbf{7 7}$ as a better forum for far-reaching talks on trade,

\footnotetext{
1 Earlier versions of this paper with more attention to 1969-79 events and negotiations were presented at the Asian Conference on Trade and Development (Marga Institute. International Centre for Law in Development Sri Lanka Foundation Institute) in Colombo in February and at seminars of the Centre for Research on the New International Economic Order in February and July 1979. These will appear as 'Trade and Development: A Conceptual Framework' in Tiruchelvam and Krishnaswamy eds. (forthcoming 1979) and Sengupta, ed. (forthcoming 1980). It makes extensive use of information and ideas from participants in these seminars and particularly of papers on the Tokyo Round of GATT by S. K. Bagch and $R$. Krishnamurti which will appear in the Sengupta volume. The author wishes to thank the participants in volume. The author wishes to thank the participants in these seminars-and in particular Kamal Hossain-for information, ideas and criticisms but remains responsible for how he has used (or misused!) them.
}

GATT is where the action is in terms of operating and modifying the existing structures.

The present context is one of a rising New Protectionism eroding the liberalised trade system built up over the period 1945-73; an erosion concealed by the bright lights of GATT where a triumphal march toward free trade is asserted to exist, even though in the dark back alleys of national (and EEC) action, those principles are increasingly being attacked; vide the 1978 version of the Multifibre Textile Arrangements (MFA), or the growing structure of 'voluntary agreements' and 'reference prices' in sectors such as steel and shipbuilding. The most endangered economies are those of the Group of 77-and especially those committed to export-oriented growth through manufacturing. The access for their exports legally available under GATT is being eroded de facto when they have the strongest need to use it and, in some cases, have built up the capacity to do so. They are in the greatest danger because the major industrial economies perceive discrimination against them as being safe. Nobody talks seriously of 'selective safeguards' against the USA or West Germany or-quite-against Japan, and the assertion of 'unfair competition' is largely either an abusive rephrasing of 'too competitive for us to match' or an hypocrisy. Whatever the limitations of neofree trade as enshrined in GATT, selective hostile discrimination (the growing alternative today) is clearly worse for the members of the Group of 77.

\section{Disorder and Containment: the North Looks Inward}

The reasons for the changed trend-changed since the Tokyo Round opened in 1973 - are not hard to find. The inflation, unemployment, slow growth, and external imbalance crisis of the industrial capitalist (and to a lesser degree industrial socialist) economies which began in the late $1960 \mathrm{~s}$ has gathered momentum and proved resistant to treatment. Meanwhile-with the sole exception of petroleum - the Southern challenge has been contained. The major capitalist industrial economies therefore see internal and North/North issues as having top priority and North/South as relatively minor. Worse, to a limited but growing extent, they see exporting 
their troubles to the South-for example, by limiting imports or cutting aid-as one of their secondary domestic options. That is why GATT itself is being eroded, why the Tokyo Round made virtually no progress on issues of primary concern to the 77, and why the emphasis was on special codes to protect North/North trade against a non-tariff barrier trade war.

From a Group of 77 (or individual South state) point of view, the most important question is what can be done now to halt, and ideally reverse, the deterioration of effective access for their exports. Whatever may be said about exportoriented growth, even the most austere and inward looking development in all but a handful of Third World states will require enhanced import capacity and, therefore, access for exports. Before looking at areas in which policy initiatives might be successful, it is desirable briefly to review the outcome of the Tokyo Round and to raise queries about the tactics used during it by GATT's Third World members.

\section{MTN: State of Play}

Most evaluations of the Tokyo Round treat its implications for the periphery as secondary, if they mention them at all. Those concentrating on Third World aspects tend to adopt a 'half full' versus 'half empty' approach to measuring results. Those written from an UNCTAD orientation (eg. that by $R$. Krishnamurti) stress the emptiness of the results, and those from a GATT perspective (eg. that by S. K. Bagchi), the fullness of the potential (both in Sengupta, ed., forthcoming 1980). It might be more useful to pose two different questions:

1. to what extent did the Tokyo Round stem the rising New International Economic Disorder and the New Protectionism?

2. to what extent did it weaken the built-in discrimination against the periphery which has historically characterised the normal working of the MTN?

The answer to the first question must be: something but not much. Tariff reductions were continued and some serious steps toward regulating, and perhaps lowering, non-tariff barriers were taken in the codes. A common front was preserved, at least verbally, against a reversion to 1930s-style trade wars and beggar-my-neighbour export promotion and import containment. But no steps were taken to increase surveillance powers or to halt back alley assaults on trade, via private cartels, quango (mixed state-private) cartels, public cartels (eg. EUROFER), 'voluntary quotas', reference prices, etc.

For the South the assessment must be even gloomier. 'Selective safeguards' as adumbrated by the EEC are a generalisation of the trade war against peripheral exporters already proceeding in textiles under the aegis of the MFA. There is strong pressure to whittle away the access legally provided under GATT, even though there is, as yet, no agreement on 'selective safeguards' or surveillance (see Herald Tribune, 24 July 1979; The Guardian, 25 July 1979).

\section{Exclusion Enhanced}

The answer to the second question must be that the Tokyo Round increased discrimination in four ways:

-there were justified complaints not only from clearly peripheral countries but even from those on the OECD periphery (like Australia ${ }^{2}$ ) and smaller industrial states (like the Nordic group), that only Japan, the EEC and the USA had been able to participate meaningfully and that all others had been presented with virtual 'take it or leave it' offers;

-tariff cuts were about 10 per cent on tropical products (raw and processed), 20 per cent on labour intensive manufactures, 40 per cent in capital intensive and high technology manufactures-precisely the pattern that has made previous MTNs far more liberalising for NorthNorth than for South to North trade;

-the codes on non-tariff barriers are very complex and, with the exception of that on government purchases, benefit only the signatories. They are drafted to meet industrial economy needs, will not really be open toor usable by-most periphery states and are drafted as self regulating, ie. they are not under general GATT surveillance. Thus they can provide cover for discrimination by signatories (industrial capitalist economies) against non-signatories (periphery economies), unlike such special provisions as the GSP and intraThird World trade preferences which are left squarely within GATT guidelines and under its surveillance;

-moves to legalise 'selective safeguards', as have been cited above.

\footnotetext{
2 Australia was-and is, fudging from recent conversations with senior personnel-particularly bitter. As a result it may well not sign the Tokyo Round agreements. It had gone with a package of offers (eg. on automobiles) and requests (e.g. on processed foods) but found nobody willing to negotiate.
} 
This record can be assessed only as increasing discrimination against the peripheral economies and eroding their right of access on equal terms to industrial capitalist economy markets.

\section{Southern Tactics and Priorities: a Critique}

In the Tokyo MTN, the South's tactics failed to achieve results and its priority changes were not achieved. It is true that the Big Three virtually ignored both the South and the guidelines which they had initially agreed and which included Southern priorities such as tropical products. It is also true that the demand for 'selective safeguards', at least in the EEC formulation, ${ }^{3}$ amounted to overt aggression both against the South and against the basic principles of GATT. In the circumstances, therefore, the South was doomed to lose, whatever its tactics. Nonetheless, a reappraisal of tactics and priorities is needed since their continued use is unlikely to yield improved results.

At least six approaches need questioning:

-the stress on preferences, and a GSP which focuses on a particular group of countries as opposed to generalised tariff cuts on goods of particular interest to one or more peripheral economies. The GSP is not generalised. It is drafted to include goods Third World countries cannot export and to limit or exclude those they can. The value to the South of any conceivable cut via the GSP is considerably smaller than the value of cutting tariffs on tropical products, processed goods, or labour intensive manufactured goods, by the same proportion as has been applied to automobiles, computers, or machine tools;

- the failure to insist on active participation in the drafting of codes on non-tariff barriers which are often more damaging to access than tariffs;

-the perception of GATT as a forum which pushes a neo-free trade line that is not helpful to developing economies and which uses procedures that make effective participation hard. While this perception is historically reasonable, the alternative to neo-free trade is currently straightforward negative discrimina-

\footnotetext{
3 The US formulation was milder and less clearly antiperiphery as was the Japanese also; they too are a potential target for selective measures. Within the EEC the hard linget for selective measures. Within the EEC the hard line proponents of selective discrimination were the UK and France-understandable again as they have the facing problems in meeting Third World (or other) competition.
}

tion, so that GATT's philosophy is at least a potential interim defense against Northern neomercantilism. With the periphery forming a majority in GATT's overall policy forum (all members), some changes in procedure might have been won and, with more periphery expert personnel, more resources might have been devoted to exploiting whatever opportunities for participation did exist;

- the stonewalling tactics on the 'differentiation' issue and its corollary, 'graduation', (whereby some middle income countries would be requested to make reciprocal trade concessions). In particular the South argued as if the choice were between 0 per cent reciprocity now and 100 per cent tomorrow, which was at least psychologically, and probably also operationaliy, unsound. Setting up unreal alternatives and a maze of technical hurdles for proponents of change is a defensive tactic for those who find the status quo acceptable or any change likely to be for the worse. For the UK at UNCTAD - given the delegation's perception of UK interests and 77 power-it was a splendid approach; for the South in the MTN it was much more questionable;

-the failure, until the Arusha 77 meeting, to develop a firm line that all trade restrictions should be brought back into the glare of GATT and out of the shadows of the back alleys (see UNCTAD (1) 1979: 30-35), which was probably very costly. The immediate danger is a continued erosion of access. 'Deals' such as the 1978 MFA between a major industrial power and a single ldc, or cartels organised by industrial economies under pressure only from anti-import interests, provide a less favourable setting for resisting such erosion than GATT whose rules and structures oppose restrictions and whose relative openness means that protrade interests can also bring influence to bear;

-only at Arusha and Manila (see UNCTAD 1979) did the 77 align themselves with OECD (Group B) calls for opposition to increased protectionism. This tardiness in making common cause on a genuinely common concern (positive sum game) prevented a real impact on what at Arusha/Manila the 77 saw as its corollary: international monitoring of special trade restrictions to ensure that they were accompanied by adjustment and were phased out and not repeated. While Group B agreed that GATT could in principle study and report, but not monitor or enforce, it was too late by the time of Manila to feed this back 
into the Tokyo MTN. In retrospect the time to have begun this line of tactics was at the 1976 Nairobi UNCTAD.

To criticise in this way is not to "blame the victim'. It is to argue that the 77 need to reconsider their tactics and priorities if they are to avert a continued worsening of access to industrial economy markets for their processed, manufactured and temperate agricultural exports and even more so if they are to have any real chance of reversing the trend. Precisely because they lack the economic power to enforce change, they have a special need to identify short and medium term common concerns and appropriate tactics for exploiting them.

\section{Where Now?}

Clearly GATT will not begin another general tariff-cutting round in the near future. The world economic situation is not propitious, the Tokyo Round's bruises are still tender, and for most manufactured goods tariffs are not the chief obstacle to trade. Equally clearly, few states find the present situation satisfactory. The New International Economic Disorder advances. The New Protectionism is in constant danger of breaking out into open trade wars. Selective safeguards without international surveillance of adjustment are manifestly cancerous and likely to spread from North-South to North-North relations. Thus there is a general concern that GATT-as the forum and flagbearer of liberal trade-should be seen to be doing something.

This context is one in which the potential for Group of 77 initiatives to make some progress is relatively good. Unlike MTN, most proposals for change would go before GATT as a whole (where the 77 are in a majority) and would not be bound so much by procedures and customs which exclude all but the Big Three. Further, the core capitalist industrial economies perceive a need to do something but do not have clear proposals which would dominate discussion because of the economic weight of their authors, whatever the merit of their content.

Clearly GATT is not a tabula rasa. It exists in the context of international economic structures and of an international economic crisis. The 77 do not have the power, in the short run or via GATT, to overturn the first nor to solve the second. Therefore, to be serious starters for normal GATT meetings or, perhaps preferably, special negotiating conferences, Group of 77 proposals must on the one hand offer a significant contribution to limiting and reversing the present crisis, and, on the other, have some element of 'mutual interest'-some gain to the industrial economies from accepting (or some loss from rejecting) them.

\section{What Themes?}

In drawing up a checklist of areas for proposal drafting and action, at least seven stand out: ${ }^{\star}$

\section{Participation}

Here the Group of 77 should make common cause with the smaller industrial (eg. Nordic) and rich peripheral (eg. Australia) states. It should use its majority in GATT to secure article and code changes. Part of the problem lies within the 77. Very few of its members can mount adequate teams to cover all GATT issues and for most only a few issues/products are critical at any one time. This implies a need for coordinated preparation-such as UNCTAD studies, a Group of 77 technical group, exchange of national work; for joint Group of 77 or sub-group positions worked out complete with tactics and fallback positions before major sessions; and for agreeing on spokesmen states on each issue so that, taken as a whole, the 77 participate coherently and forcefully across the board.

\section{Illumination}

Unless neo-mercantilism, the New Protectionism and bush fire trade wars or worse are to triumph, it is vital to get 'trade restrictionism' back into the glare of GATT where it may be possible to transmute it into some less damaging (and over the long run positively beneficial) form of 'trade management'. This is a common interest areaespecially for the exporters of the North. It requires that 'management' of trade be accepted as a fact, subjected to formal GATT guidelines, negotiated in GATT fora serviced by the GATT Secretariat, ${ }^{5}$ and monitored via, and subject to challenge in, GATT fora. This exists already for tariff barriers but there is an urgent need to extend coverage to 'cartels', 'voluntary agreements', 'negotiated quotas', and to put an end to back alley knifing of trade and to the ultimate obscenity, which is to have coercive, trade destructive arrangements like the MFA of 1978 - which deny all principles of managed or liberal trade-registered as GATT protocols.

\footnotetext{
4 Some of these areas are treated in more detail in the author's paper in Sensupta (forthcoming 1980).

5 The GATT Secretariat, ironically. prefers cartel talks (eg. the abortive OECD feelers in respect to steel) and trade destruction schemes (eg. MFA) to be negotiated outside GATT. This attempt to keep GATT's hands clean. however. seenis reminiscent of the traditional ost rich with its head in the sand. Or of Pontius Pilate-not an effective wav of protecting neo-free trade or transmuting it to managed trade.
} 
GATT supervision of 'adjustment'

Safeguard clauses will remain. The present GATT formulations are unsound. A system which allowed selective safeguards under clear guidelines would be an improvement on the status quo. Such guidelines would involve prior negotiations, effective compensation, and a requirement that selective imposition against one state would involve imposition against all larger import flows.

It is essential to rebut and to block action on the EEC's claim that it always has imposed selective safeguards (partly true), will continue to do so (only too true) and has the right to do so as it sees fit under GATT (totally at variance with the Articles). But a quid pro quo, which is also in the mutual interest of both sides, is that GATT should have guidelines for, and at least investigatory and reporting (preferably surveillance and adjudication) powers over, 'adjustment' measures and safeguards. These should include time limits, staged phase-out, bars to reimposition, and requirements for national measures adequate to make a return to liberal trade practicable at the end of the 'safeguard' restriction period. Such restrictions and guidelines-in a tighter formdo exist within economic unions (eg. the EEC); they are necessary if 'liberalising' the right to invoke safeguards is not to be destructive of international trade in general.

\section{Protocol participation and monitoring}

The codes on non-tariff barriers are potentially valuable to Group of 77 members. But to exploit that potential, revisions are needed. First, the codes should not be in self-governing protocols administered by signatories only, but dependent on GATT articles and on challenge and monitoring by GATT (like GSP and economic cooperation among developing countries, or ECDC). Second, the operation of the codes should be made less complex so that interested Group of 77 members could join and participate. In particular, they should have provision for 'protocol management committees' with a membership that reflects the various interest groupscore OECD, rich periphery, NICs, OPEC, core 77-rather than simply the balance of protocol signatories. This approach is analogous to that of the Committee of 15 for GATT itself. Third, the approach of the Government Purchases Code which extends its benefits to non-signatory ldcs should be extended to the other codes/protocol.

\section{Redress past discrimination}

The 77 should propose that the degree of tariff cuts on all classes of products and major items over the life of GATT be analysed with a view to equalising the reduction in tariff protection accorded them. This would demonstrate how selectively and systematically GATT cuts have been biased against tropical products, processed raw materials, and labour intensive manufactures, and it would lay a foundation for concrete proposals to phase out that bias by selective tariff cuts.

\section{Differentiation, graduation and reciprocity}

Clearly the 77 are not identical in economic structure, productive force or strength. Clearly also at some point reciprocity needs to be phased in by a rapidly developing manufactured goods exporter. To attempt to deny these realities simply opens the 77 to semi-covert pressures for bilateral concessions and the risk of open, unilateral 'reciprocity imposition' by the Big Three. Serious thought needs to be given to the 77's proposals for guidelines. These might include: defining an intermediate category of states (in terms of GDP per capita, and share of manufactures in GDP and exports); requiring such states, however defined, to offer GSP; and requiring reciprocity on those manufactured goods in which they had a substantial export surplus and export volume. Such a positive approach would be tactically, psychologically and, hopefully, substantively sounder than stone-walling.

\section{Adjudication}

If GATT is to be effective in monitoring and surveillance on a broader front (eg. safeguards, adjustment, non tariff barriers, phasing in reciprocity) it needs more than guidelines. It needs a capacity to collect and interpret data in a way which neither views the very idea of 'management' as a departure from the Holy Grail of Pure Free Trade (the present GATT Secretariat position) nor sees any and all manipulative destruction of trade measures as inevitable concomitants of 'managed free trade' (the apparent EEC position). But even more, it needs rules and fora for processing and adjudicating on challenges promptly and coherently. The details need clarification and articulation; the need is clear.

If the Group of 77 is to take the initiative in GATT, it should encourage its non-GATT members to get in and add their voices (and votes) and also take a lead in seeing that adequate preparation of proposals is done by a technical group of the 77, by UNCTAD on contract, and by member states. Equally it should seek to build up support for its approach by liaison with states like Australia, Canada, New Zealand, Turkey and the Nordic group which in many respects have similar concerns. Probably a 77 trade 
ministers' meeting (like Arusha) will be needed after officials have sketched an agenda and documentation. Certainly getting a set of proposals to the Group of 77 members of the GATT Committee of 15 in the first half of 1980 would be a desirable step toward achieving a positive trend in GATT and in trade.

\section{Contexts and Limits}

These suggestions, even if pursued successfully, would not achieve the New International Economic Order-much less the new Jerusalem. Nor do they purport to be a complete checklist for international economic policy initiatives by the Group of 77 collectively or individually. ECDC, finance, technology transfer, transfer pricing and restrictive business practices are all critical areas for which similar limits are needed. However, the substance of ECDC is no more a topic for global fora than is the EEC (possibly both should be, but not ECDC alone) and the others are on the agenda of fora other than GATT.

The purposes for pursuing initiatives along the lines suggested would be:

- crisis management and damage containment against the New International Economic Disorder and the New Protectionism;

-creating a basis on which restructuring out of recession-eg. Global Keynesianism, two way NICs-OECD core trade expansion-has a better chance of being explored seriously;

-reversing the trend toward the increasing marginalisation and diminishing participation of states outside the Big Three (USA, Japan, EEC) in decisions and structures affecting/regulating international trade;

- seeking to reduce both the impact of unwelcome stochastic shocks and the pressures for unilateral trade destruction to resolve domestic problems by introducing minimum elements of collective management (indicative planning) into international trade frameworks.

These are limited purposes. However, they are also potentially attainable ones which could produce direct benefits and create a context in which more far-reaching changes would have a better chance of receiving serious positive consideration.

\section{References}

The Guardian, 25 July 1979, 'Multilateral Trade Talks Break Down'

Herald Tribune, 24 July 1979, 'World Trade Talks Fail to Set Safeguards'

Sengupta, A. K., (ed.), forthcoming 1980, Commodities, Finance and Trade, Francis Pinter, London

Tiruchelvam, N. and R. Krishnaswamy, forthcoming 1979, Trade and Development, Marga, Colombo

UNCTAD, 1979, Developments in International Trade: Protectionism, [Draft Resolution-subsequently passed], (TD/L 188), Geneva

-(1) 1979, see Editorial references 